\title{
The association of the hydration status and parental knowledge on fluid consumption with children's weight status in Malaysia
}

\author{
*Satvinder Kaur ${ }^{1}$, Serene Tung ${ }^{1}$, Dhivyalosini Maykanathan ${ }^{1}$, Yi Yan Lim ${ }^{1}$ \\ Sri Lanka Journal of Child Health, 2017; 46(3): 222-229
}

\begin{abstract}
Introduction: Hydration and obesity play an important role in body weight regulation.

Objective: To determine the association of hydration status and parental knowledge on fluid intake with the children's weight status in Muar, Johor, Malaysia.
\end{abstract}

Method: A total of 207 children, 7-13 years of age, and their parents participated in this crosssectional study. Parental fluid consumption knowledge questionnaire and beverage questionnaire were used to assess parent's knowledge on fluid consumption and children's fluid intake consumption, respectively. Body weight and height were measured and body mass index (BMI) was calculated.

Results: A total of $24.7 \%$ of the children were overweight. Majority (78.7\%) of the children were insufficiently hydrated while $78.7 \%$ parents had poor fluid consumption knowledge. Parental fluid consumption knowledge was associated with children's hydration status $\left(\chi^{2}=47.788\right.$; $\mathrm{p}<0.001)$ as significantly more parents had good knowledge on fluid consumption when children were sufficiently hydrated (59\%) compared to insufficiently hydrated (11\%). Similarly, hydration status was associated with children's BMI $\left(\chi^{2}=9.065 ; p=0.011\right)$ where significantly more overweight children were insufficiently hydrated $(88.5 \%)$ compared to sufficiently hydrated children.

\footnotetext{
${ }^{1}$ UCSI University, Malaysia

*Correspondence:

satvinderkaur@ucsiuniversity.edu.my

(Received on 23 September 2016: Accepted after revision on 18 November 2016)

The authors declare that there are no conflicts of interest

Personal funding was used for the project.

Open Access Article published under the Creative

Commons Attribution CC-BY (cC) (i)
}

Conclusion: Parental fluid consumption knowledge was significantly associated with children's hydration status. Hydration status was significantly associated with children's BMI.

DOI: http://dx.doi.org/10.4038/sljch.v46i3.8322

(Keywords: Hydration, children, parental fluid knowledge, Malaysia, BMI)

\section{Introduction}

In Malaysia, the prevalence of overweight and obesity in children was reported to have increased from $20.7 \%$ in 2002 to $26.5 \%$ in $2008^{1}$ and to $28.9 \%$ in $2013^{1,2}$. Focusing on dietary intake of growing children is vital with more emphasis given to the basics of nutrition such as hydration ${ }^{3}$. The impact of water intake on energy consumption was mostly done among adults and water was found to have positive impact on body weight regulation ${ }^{4}$. According to Popkin BM et al, there was a fairly complex linkage found between water consumption and energy intake ${ }^{5}$. It was suggested that the risk for school children getting overweight could be reduced by $31 \%$ if they had good hydration status. It was also found that drinking water can fulfil hydration requirement without providing any additional energy $^{6}$. The role of water in regulating body weight was shown by Muckelbauer $\mathrm{R}$ et al. whereby dehydrated children are more likely to be overweight ${ }^{3}$. Children with lower hydration status are more likely to consume higher energy intake while children with higher hydration status would have healthier dietary choices ${ }^{3}$.

Although parents' general nutrition knowledge may not affect their children's diet, $75 \%$ of studies showed that parents' nutrition knowledge has implication on their child health outcomes ${ }^{7}$. Beverages are significant in a child's diet, making it almost $20 \%$ of energy contributor for children's intake ${ }^{3}$. Parents believed that serving sweetened drinks such as cordial is a method to provide fluid for their children ${ }^{8}$. Sugar sweetened beverages (SSB) have been found through meta- 
analysis to be a main contributor to weight gain among children'; hence water should be the main source of hydration to help curb obesity among this group.

Despite such findings in the past, there is lack of published studies examining hydration status of the children and parents' knowledge on fluid consumption in relation to children's weight status in Malaysia. Hence, there is a need to determine the relationship between parents' knowledge on fluid consumption with hydration and weight.

\section{Objective}

To assess parents' knowledge on fluid consumption, hydration status and weight status of children in Johor Bahru, Malaysia.

\section{Method \\ Study setting and subjects}

This study was approved by the Ethics Committee of Research and Scholarly Activities (RSA) of the Faculty of Applied Sciences, UCSI University. Approval to conduct the study in respective tuition/learning centres in Johor Bahru, Malaysia was obtained from respective centres. Respondents and their parents were informed of the purpose of this study through information sheets distributed to the school children in the learning centres. Signed consent forms were obtained from the respondents and their parents prior to the data collection.

This is a cross-sectional study conducted in tuition/learning centres among children and adolescents aged 7 to 13 years old in the state of Johor Bahru, Malaysia. Respondents were recruited using a convenience sampling method whereby 6 tuition/learning centres were approached. All children from all classes in the tuition/learning centres were invited to participate. Teachers distributed parental consent forms to parents via the students. A total of 207 child-parent pairs provided their consent to participate in the study. Data collection commenced in October and was completed in November 2014.

\section{Parent-administered questionnaire}

Socio-demographic background: This section consisted of six questions that were used to assess the socio-demographic background of the parent and child. The information gathered were mainly date of birth of the child, age of the child, gender of the child, parent's highest educational level, parent's occupation and household monthly income.

Parents' fluid consumption knowledge: Parent's fluid consumption knowledge is a selfadministered questionnaire created specifically for this study according to the "Healthy Hydration Guide for Children aged 4-13 years"10 to obtain the knowledge of parents on fluid consumption. Parents' knowledge was assessed through fifteen statements about common knowledge on fluid intake for their growing children. Example of statements included: "Drinking extra water or forced drinking when not thirsty is a way to lose weight'. Response options were correct (1), incorrect (0) or did not know the answer $(0)$, and were then summed to compute a total score on knowledge with minimum score of 0 and a maximum score of 15 . The overall fluid knowledge scores were later categorized as poor (less than 11), satisfactory (11-12) and good (more than 12).

Daily fluid intake of children: Beverage Intake Questionnaire (BEVQ-15) is a brief selfadministered questionnaire used to assess habitual beverage intake of children ${ }^{11}$. It is a semi-quantitative food frequency questionnaire that estimates habitual mean daily intake of water, total beverages and sugar-sweetened beverages. The original BEVQ-15 consisted of fifteen beverage categories including water, $100 \%$ fruit juice, sweetened juice beverage or drink, whole milk, reduced fat milk, low fat/fat free milk, soft drinks, diet soft drinks/artificially sweetened drinks, sweetened tea, tea or coffee with cream or super, tea or coffee black with/without artificial sweetener, alcoholic drinks such as beer, hard liquor, wine and lastly energy/sport drinks. For the purpose of this study, three categories of the alcoholic beverages namely beer, hard liquor and wine were excluded so that only twelve categories of beverages were used to assess the habitual beverage intake of the children. Respondents were asked to indicate "how often" and "how much" of a beverage they consumed in the past week. Responses for "how often" category ranged from "never or less than once per week" up to " $3+$ times per day"; "how much" ranged from "less than $3 / 4$ cup" up to "more than $2 \frac{1}{2}$ cups". The amount of fluid consumed by children per day was calculated from total fluid intake per week divided by 7 days. The children who met the daily fluid intake 
requirements according to the Malaysian Dietary Guidelines for Children and Adolescents ${ }^{12}$ were classified as sufficiently hydrated while those that did not meet the guidelines were classified as insufficiently hydrated.

\section{Anthropometric Measurements}

Body weights of the respondents were measured to the nearest $0.1 \mathrm{~kg}$ using OMRON Bioelectrical Impedance Analyser (BIA) (Model HBF-356, Japan). Height was measured to the nearest 0.1 $\mathrm{cm}$ using a SECA Body Meter 206. Body mass index (BMI) was calculated and weight status of the respondents was determined according to the International Obesity Task Force (IOTF) definitions of overweight and obesity in children and adolescents ${ }^{13}$. The waist circumferences of the children were measured using a body measuring tape to the nearest $0.1 \mathrm{~cm}$ to determine abdominal obesity. The $90^{\text {th }}$ percentile was used as the cut-off point to assess abdominal obesity $^{14}$.

\section{Data Analysis}

Data were analyzed using IBM SPSS Statistics (Version 22.0). Frequency was used to present the demographic characteristics of the subjects. Independent samples T-test was used to determine the mean difference of anthropometric measurements, parents' knowledge on fluid consumption and daily fluid intake of the children between the male and female subjects. Chi-square analysis was conducted to examine the association between parents' knowledge on fluid consumption and hydration status of the children. Independent T-test and One-way ANOVA were used to compare the differences in BMI for socio-demographic factors, parents' knowledge on fluid intake and hydration status. Pearson correlation was used to determine the correlation between daily fluid intakes with BMI. Statistical significance was set at $\mathrm{p}<0.05$.

\section{Results}

A total of 207 children (7-13 years of age) and their parents consented and completed the study. The socio-demographic characteristics of the respondents are shown in Table 1. The mean age of the children was $9.73 \pm 1.99$ years.

Table 1

Socio-demographic characteristics of respondents $(n=207)$

\begin{tabular}{|l|c|}
\hline $\begin{array}{l}\text { Socio-demographic } \\
\text { characteristic }\end{array}$ & Number (\%) \\
\hline Child Gender & $112(54.1)$ \\
Male & $95(45.9)$ \\
Female & $30(14.5)$ \\
\hline Age (years) & $48(23.2)$ \\
07 & $25(12.1)$ \\
08 & $19(09.2)$ \\
09 & $37(17.9)$ \\
10 & $25(12.1$ \\
11 & $23(11.1)$ \\
12 & \\
13 & $19(09.2)$ \\
\hline Ethnicity & $186(89.9)$ \\
Malay & $02(01.0)$ \\
Chinese & \\
Indian & $34(16.4)$ \\
\hline Parent gender & $173(83.6)$ \\
Male & \\
Female & $24(11.6)$ \\
\hline Parent educational level & $87(42.0)$ \\
Primary & $42(20.3)$ \\
Secondary education & $10(19.3)$ \\
Pre-university & $14(06.8)$ \\
Degree & \\
Masters \& PhD & $17(08.2)$ \\
\hline Monthly household income & $38(18.4)$ \\
< RM1500 & $57(27.5)$ \\
RM1500- RM2999 & $30(14.5)$ \\
RM3000- RM4499 & $65(31.4)$ \\
RM4500- RM5999 RM6000 & \\
Note: RM 1500=USD 360; $R M$ 3000 USD 767; \\
RM 4500=USD 1151; RM 6000=USD 1533
\end{tabular}

The anthropometric indices, daily fluid intake and parents' knowledge on fluid consumption are presented in Table 2. 
Table 2: Mean values and distribution of anthropometric indices, daily fluid intake and parents' knowledge on fluid consumption

\begin{tabular}{|l|c|c|c|}
\hline \multicolumn{1}{|c|}{ Factor } & Male $(n=112)$ & Female $(n=95)$ & Total \\
\hline Height $(\mathrm{cm})$ & & & \\
Mean $\pm \mathrm{SD}$ & $137.60 \pm 13.90$ & $135.93 \pm 15.07$ & $136.84 \pm 14.43$ \\
\hline Weight $(\mathrm{kg})$ & $35.07 \pm 11.16$ & $33.21 \pm 11.53$ & $34.22 \pm 11.34$ \\
Mean \pm SD & $13(11.6 \%)$ & $09(09.5 \%)$ & $22(10.6 \%)$ \\
\hline Body mass index $\left(\mathrm{kg} / \mathrm{m}^{2}\right)$ & $68(60.7 \%)$ & $66(69.5 \%)$ & $134(64.7 \%)$ \\
Thinness & $22(19.7 \%)$ & $16(16.8 \%)$ & $38(18.4 \%)$ \\
Normal weight & $09(08.0 \%)$ & $04(04.2 \%)$ & $13(06.3 \%)$ \\
Overweight & $18.32 \pm 4.76$ & $17.55 \pm 3.52$ & $17.97 \pm 4.24$ \\
Obese & & & \\
Mean \pm SD & $101(90.2 \%)$ & $82(86.3 \%)$ & $183(88.4 \%)$ \\
\hline Waist circumference $(\mathrm{cm})$ & $11(09.8 \%)$ & $13(13.7 \%)$ & $24(11.6 \%)$ \\
Normal & $62.30 \pm 10.44$ & $60.19 \pm 9.37$ & $61.33 \pm 9.99$ \\
Abdominal obesity & $89(79.5 \%)$ & $74(77.9 \%)$ & $163(78.7 \%)$ \\
Mean \pm SD & $23(20.5 \%)$ & $21(22.1 \%)$ & $44(21.3 \%)$ \\
\hline Parents' knowledge on fluid consumption & $8.88 \pm 2.03$ & $8.73 \pm 2.22$ & $8.81 \pm 2.12$ \\
Poor & & & \\
Good/Satisfactory & & & \\
Mean \pm SD & &
\end{tabular}

Boys had slightly higher anthropometric indices (height, weight, body mass index, waist circumference) compared to girls but the differences were not statistically significant ( $>0.05$ ). The mean score of parent's knowledge on fluid consumption was slightly higher among the boys compared to girls although no significant difference was found $(\mathrm{p}>0.05)$.
Majority (78.7\%) of the parents had poor knowledge on fluid consumption.

Daily fluid intakes of the respondents are presented in Table 3. Parents' knowledge on fluid consumption according to hydration status is presented in Table 4.

Table 3: Daily fluid intake and hydration status of the respondents

\begin{tabular}{|l|c|c|c|}
\hline \multicolumn{1}{|c|}{ Daily fluid intake $(\mathrm{ml} /$ day $)$} & Male $(n=112)$ & Female $(n=95)$ & Total $(n=207)$ \\
\hline Water & $870.18 \pm 334.55$ & $829.89 \pm 339.92$ & $851.69 \pm 336.80$ \\
\hline $100 \%$ Fruit juice & $122.86 \pm 180.23$ & $137.89 \pm 173.95$ & $129.76 \pm 177.11$ \\
\hline Sweetened juice beverage & $41.70 \pm 112.94$ & $41.27 \pm 87.25$ & $41.50 \pm 101.72$ \\
\hline Whole milk & $185.00 \pm 165.55$ & $149.79 \pm 172.45$ & $168.84 \pm 169.25$ \\
\hline Reduced fat milk & $12.59 \pm 47.30$ & $16.11 \pm 73.46$ & $14.20 \pm 60.60$ \\
\hline Fat free milk & $50.90 \pm 118.95$ & $30.42 \pm 82.22$ & $41.50 \pm 103.98$ \\
\hline Soft drinks & $24.41 \pm 73.67$ & $38.53 \pm 105.78$ & $30.89 \pm 89.89$ \\
\hline Sweetened tea or coffee & $20.89 \pm 79.30$ & $7.26 \pm 31.61$ & $14.64 \pm 62.37$ \\
\hline Tea or coffee with cream & $20.98 \pm 70.48$ & $7.98 \pm 42.47$ & $15.05 \pm 59.58$ \\
\hline Energy \& sports drinks & $12.68 \pm 45.00$ & $15.47 \pm 55.02$ & $13.96 \pm 49.74$ \\
\hline Total fluid intake & $\mathbf{1 3 3 7 . 9 8} \pm \mathbf{5 5 6 . 1 4}$ & $\mathbf{1 2 8 2 . 6 6} \pm \mathbf{5 4 0 . 3 2}$ & $\mathbf{1 3 3 4 . 4 9} \pm \mathbf{5 4 9 . 7 1}$ \\
\hline Hydration status & & & \\
Sufficiently hydrated & $24(21.4 \%)$ & $20(21.1 \%)$ & $44(21.3 \%)$ \\
Insufficiently hydrated & $88(78.6 \%)$ & $75(78.9 \%)$ & $163(78.7 \%)$ \\
\hline
\end{tabular}

Table 4: Parents' knowledge on fluid consumption and hydration status of the children

\begin{tabular}{|l|c|c|c|c|}
\hline \multirow{2}{*}{ Parent's knowledge } & \multicolumn{2}{|c|}{ Hydration status } & \multirow{2}{*}{$\chi^{2}$} & p-value \\
\cline { 2 - 3 } & Sufficiently hydrated & Insufficiently hydrated & & \\
\hline Poor & $18(40.9 \%)$ & $145(89.0 \%)$ & 47.788 & $<0.001$ \\
Good/Satisfactory & $26(59.1 \%)$ & $18(11.0 \%)$ & & \\
\hline
\end{tabular}


A Chi-square analysis was conducted and significantly more parents had good knowledge on fluid consumption when the children were sufficiently hydrated $(59.1 \%)$ compared to insufficiently hydrated $(11 \%) \quad\left(\chi^{2}=47.788\right.$; $\mathrm{p}<0.001)$.

The highest source of fluid intake came from water $(851.69 \pm 336.80 \mathrm{ml} /$ day $)$ followed by whole milk (168.84 $\pm 169.25 \mathrm{ml} /$ day $)$ and $100 \%$ fruit juice $(129.76 \pm 177.11 \mathrm{ml} /$ day $)$. The least consumed beverages were sweetened tea $(9.76 \pm 44.19 \mathrm{ml} /$ day $), \quad$ regular coffee/tea
$(4.88 \pm 38.39 \mathrm{ml} /$ day $)$ and diet soft drinks $(2.13 \pm 15.37 \mathrm{ml} /$ day $)$. The mean of total fluid intake for the boys $(1337.98 \pm 556.14 \mathrm{ml} /$ day $)$ was slightly higher than girls $(1282.66 \pm 540.32$ $\mathrm{ml} /$ day) although no significant difference was found ( $\mathrm{p}>0.05)$.

In the bivariate analysis (Table 5), child's age $(r=0.276, p=0.000)$ correlated with children's BMI. For daily fluid intake, only $100 \%$ fruit juice $(r=-0.149 ; p=0.032)$ negatively correlated with children's BMI.

Table 5: Associations between socio-demographic factors, daily fluid intake and parent's knowledge on fluid consumption with BMI

\begin{tabular}{|l|c|c|}
\hline \multicolumn{1}{|c|}{ Variables } & \multicolumn{1}{c|}{ Body Mass Index } \\
\hline \multicolumn{1}{|c|}{ Socio-demographic factors } \\
\hline & 0.276 & p-value \\
\hline Age & 1.315 & $0.000 \dagger$ \\
\hline Gender & 1.708 & 0.190 \\
\hline Ethnicity & 0.036 & 0.184 \\
\hline Parents education & 1.967 & 0.604 \\
\hline Household income & \multicolumn{2}{c|}{} \\
\hline \multicolumn{1}{|c|}{ Daily fluid intake } \\
\hline Water & -0.014 & 0.101 \\
\hline 100\% Fruit juice & -0.149 & $0.032 \dagger$ \\
\hline Sweetened juice beverage & -0.010 & 0.887 \\
\hline Whole milk & -0.116 & 0.096 \\
\hline Reduced fat milk & -0.016 & 0.822 \\
\hline Fat free milk & 0.065 & 0.354 \\
\hline Regular soft drinks & -0.012 & 0.862 \\
\hline Sweetened tea or coffee & -0.011 & 0.876 \\
\hline Tea or coffee with creamer & -0.057 & 0.418 \\
\hline Energy \& sports drinks & -0.004 & 0.956 \\
\hline Total fluid intake & -0.105 & 0.133 \\
\hline Parents' knowledge on fluid intake & -1.799 & 0.073 \\
\hline
\end{tabular}

*Significant association was determined by Independent T-test, $p<0.05$

$\dagger$ Significant association was determined by Pearson's correlation analysis, $p<0.05$

Hydration status and weight status are presented in Table 6. A chi-square analysis was conducted and significantly more overweight children insufficiently hydrated $(88.5 \%)$ compared to sufficiently hydrated $\left(\chi^{2}=9.065 ; \mathrm{p}<0.05\right)$.

Table 6: Hydration status and weight status of the children

\begin{tabular}{|l|c|c|c|c|c|}
\hline \multirow{2}{*}{ Hydration status } & \multicolumn{3}{|c|}{ Weight Status } & \multirow{2}{*}{$\chi^{2}$} & \multirow{2}{*}{ p-value } \\
\cline { 2 - 4 } & Underweight & Normal & Overweight & & \\
\hline Sufficiently hydrated & $7(31.8)$ & $39(31.5)$ & $7(11.5)$ & \multirow{2}{*}{9.065} & $0.011^{*}$ \\
\hline Insufficiently hydrated & $15(68.2)$ & $85(68.5)$ & $54(88.5)$ & & \\
\hline
\end{tabular}

* Significant difference was determined at $\mathrm{p}<0.05$ 


\section{Discussion}

The prevalence of overweight and obesity in this study $(24.7 \%)$ was slightly higher compared to a large nutrition survey conducted among Malaysian children $(21.6 \%)^{2}$. The prevalence of overweight and obese children was higher among boys $(27.6 \%)$ than girls $(21 \%)$. This finding is consistent with past findings ${ }^{14}$ where the prevalence of obesity was higher among the boys than the girls.

In our study, majority (78.7\%) of the parents had poor fluid consumption knowledge, whilst $21.3 \%$ had satisfactory and good fluid consumption knowledge. It was found that although no significant differences was observed in parents' fluid consumption knowledge with their children's weight status, the percentage of overweight and obese in children was found to be the highest in those parents with poor fluid consumption knowledge. This is supported by the study of Bar-David $\mathrm{Y}$ et a ${ }^{15}$ which stated that parents' fluid consumption knowledge was positively associated with children daily fluid intake and thus their hydration status.

Parents' fluid consumption knowledge was found to be associated with children's hydration status in the present study. Most of the children (74.4\%) were not sufficiently hydrated if their parents had poor fluid consumption knowledge while for those parents with higher fluid consumption knowledge; most of their children were sufficiently hydrated. This finding can be supported by the study from Bar-David Y et al ${ }^{15}$ that found poor knowledge of children hydration requirement in parents will lead to an adverse effect of inadequate hydration in their children. Moreover, the knowledge on fluid consumption was found to be important to parents as the misunderstanding of the importance of fluid or the parents do not promote fluid intake would eventually cause the children to develop unhealthy drinking habits and thus consume inadequate amount of fluids throughout the day ${ }^{16}$.

Popkin BM, et al. suggested that the risk for school age children being overweight or obese could be reduced by $31 \%$ if they had good hydration status 5 . In our study, hydration status of the children was found to be associated with children's weight status. Furthermore, Armstrong LE, et al. suggested that water can reduce energy intake when it is consumed in place of sugar-sweetened beverages, juice, and milk ${ }^{17}$. Children given sugar sweetened beverages (SSB) and non-caloric artificially sweetened drink showed that those consumed SSB had more weight gain and higher fat deposition after 18 months of the trial ${ }^{18}$. This could be explained as those given unsweetened beverages had similar satiety with those given SSBs. Hence, children are unlikely to substitute with eating more food among those given unsweetened beverage leading to lower body fat in comparison to the SSB group ${ }^{19}$.

There are some limitations in the present study. Firstly, the respondents were mainly Malay and Chinese in ethnicity with only two Indians so that Indians were under-represented. Secondly, participants were chosen only from one state in Malaysia and the findings may not apply to the whole population of children in Malaysia. Thirdly, recall bias may be possible as respondents might not remember fully the amount and frequency of the different types of fluid they consumed in the past week.

To our knowledge, this is the first study that examined the relationship between parents' knowledge on fluid consumption with hydration status and weight among Malaysian children. The findings from the present study highlight the importance of parents' fluid consumption knowledge in association with hydration status and weight status of the children. Parents with higher fluid consumption knowledge level were found to have children with better hydration status and weight status. Therefore, parents should be targeted to improve their knowledge and education on the importance of frequent fluid intake for the betterment of their children's health. In a nutshell, the relationship between BMI of children and parents' fluid consumption knowledge generated from self-composed questionnaire are not fully resolved. The need for further studies to investigate parents' fluid consumption knowledge is clear. The development of a more reliable and predictive as well as valid questionnaire for parents' fluid consumption knowledge is needed.

\section{Conclusions}

Parental fluid consumption knowledge was significantly associated with children's hydration status. Hydration status was significantly associated with children's BMI. 


\section{References}

1. Ismail M, Mazlan MN, Norimah A, Poh B, Raduan S, Ruzita A, et al. Prevalence and trends of overweight and obesity in two cross-sectional studies of Malaysian children 2002-2008. MASO 2009 Scientific Conference on Obesity and Our Environment, Malaysia, August 26-27, 2009.

2. Poh BK, Ng BK, Haslinda MDS, Shanita SN, Wong JE, Budin SB, et al. Nutritional status and dietary intakes of children aged 6 months to 12 years: findings of the Nutrition Survey of Malaysian Children (SEANUTS Malaysia). British Journal of Nutrition. 2013; 110(S3): S21-S35. https://doi.org/10.1017/S000711451300 2092

PMid: 24016764

3. Muckelbauer R, Kersting $\mathrm{M}$, and Muller-Nordhorn J. Beverage interventions to prevent child obesity. Global Perspectives on Childhood Obesity 2011; 36: 389-99.

https://doi.org/10.1016/B978-0-12374995-6.10036-2

4. Daniel MC, Popkins BM. The impact of water intake on energy intake and weight status: a systematic review. Nutrition Reviews. 2010; 68(9):505-21. https://doi.org/10.1111/j.17534887.2010.00311.x PMid: 20796216 PMCid: PMC2929932

5. Popkin BM, D'Anci KE, Rosenberg IH. Water, hydration, and health. Nutrition Reviews. 2010; 68(8):439-58. https://doi.org/10.1111/j.17534887.2010.00304.x PMid: 20646222 PMCid: PMC2908954

6. Gibson-Moore H. Hydration and health. Nutrition Bulletin. 2013; 39:4-8. https://doi.org/10.1111/nbu.12039

7. Peters J, Dollman J, Petkov J, Parletta N. Associations between parenting styles and nutrition knowledge and 2-5-yearold children's fruit, vegetable and noncore food consumption. Public Health Nutrition. 2012; 16(11), 1979-87.
https://doi.org/10.1017/S136898001200 4648

PMid: 23089340

8. Pescud M, Pettigrew S, Henley N. Nutrition beliefs of disadvantaged parents of overweight children. Health Education Journal 2014; 73(2): 201-8. https://doi.org/10.1177/0017896912471 036

9. Malik VS, Pan A, Willett WC, Hu FB. Sugar-sweetened beverages and weight gain in children and adults: a systematic review and meta-analysis. American Journal of Clinical Nutrition 2013; 98:1084-102.

https://doi.org/10.3945/ajcn.113.058362 PMid: 23966427 PMCid: PMC3778861

10. Gibson-Moore H. Improving hydration in children: A sensible guide. Nutrition Bulletin. 2013; 38: 236-242.

https://doi.org/10.1111/nbu.12028

11. Hedrick VE, Comber DL, Davy BM, Flack KD, Estabrooks PA, Nsiah-Kumi PA, et al. Development of a brief questionnaire to assess habitual beverage intake (BEVQ-15): Sugarsweetened beverages and total beverage energy intake. Journal of Academy of Nutrition and Dietetics 2012; 112(6): 840-9.

https://doi.org/10.1016/j.jand.2012.01.0 23

PMid: 22709811 PMCid: PMC3379009

12. NCCFN (National Coordinating Committee of Food and Nutrition). Recommended Nutrient Intakes of Malaysia (RNI). A Report of the Technical Working Group on Nutritional Guidelines. Ministry of Health Malaysia, Putrajaya. 2005.

13. Cole TJ, Bellizzi MC, Flegal KM, Dietz WH. Establishing a standard definition for child overweight and obesity worldwide: International survey. British Medical Journal 2000; 320: 1240-3. https://doi.org/10.1136/bmj.320.7244.1 240

PMid: 10797032 PMCid: PMC27365 
14. Khor GL, Chee WSS, Poh BK, Rahman JA, Shariff ZM, Arumugam M, et al. High prevalence of vitamin D insufficiency and its association with BMI-for-age among primary school children in Kuala Lumpur, Malaysia. BMC Public Health. 2011; 11(1):95. https://doi.org/10.1186/1471-2458-1195

PMid: 21310082 PMCid: PMC3045951

15. Bar-David Y, Landau D, Bar-David Z, Pilpel D, Urkin J. Voluntary dehydration among elementary school children residing in a hot arid environment. Journal of Human Nutrition and Dietetics. 2009; 22:45560.

https://doi.org/10.1111/j.1365277X.200 9.00960.x

PMid: 19486262

16. Molloy CJ, Cunningham C, Gandy J, Slattery CG. An exploration of factors that influence the regular consumption of water by Irish primary school children. Journal of Human Nutrition and Dietetics. 2008; 21:512-5.

https://doi.org/10.1111/j.1365277X.200 8.00880.x

PMid: 18833589
17. Armstrong LE, Barquera S, Duhamel JF, Hardinsyah R, Haslam D, Lafontan M. Recommendations for healthier hydration: addressing the public health issues of obesity and type 2 diabetes. Clinical Obesity. 2013; 2:115-24. https://doi.org/10.1111/cob.12006 PMid: 25586246

18. Borys JM, de Ruyter JC, Finch HC, Harper PC, Levy ED, Mayer JC, et al. Hydration and obesity prevention. Obesity Facts 2014; 7 (suppl 2):37-48. https://doi.org/10.1159/000360748 PMid: 24853350

19. De Ruyter JC, Katan MB, Kuijper LDJ, Liem DG, Olthof MR. The Effect of sugar-free versus sugar-sweetened beverages on satiety, liking and wanting: An 18 Month Randomized DoubleBlind Trial in Children. PLoS ONE. 2013; 8(10): e78039.

https://doi.org/10.1371/journal.pone.00 78039

PMid: 24167595 PMCid: PMC380560 